Archived version from NCDOCKS Institutional Repository http://libres.uncg.edu/ir/asu/

Williams, Marian R. (2003). The effect of pretrial detention on imprisonment decisions. Criminal Justice Review, 28, 299-317. Version of record available from Sage Publications. [ISSN: 0734-0168], [doi:10.1177/073401680302800206].

\title{
THE EFFECT OF PRETRIAL DETENTION ON IMPRISONMENT DECISIONS
}

\author{
Marian R. Williams
}

\begin{abstract}
:
A number of studies have addressed the respective influences of such legal factors as offense seriousness, and such extralegal factors as race, on imprisonment decisions. One factor that is not easily classified as either legal or extralegal-pretrial detention-has not received as much attention as the "typical" legal and extralegal variables, although some researchers feel that pretrial detention plays a pivotal role in imprisonment decisions. This exploratory article assesses the relationship between pretrial detention and the decision to incarcerate in adult felony cases in a Florida county, controlling for various legal and extralegal factors. Results indicate that those defendants who had been subject to pretrial detention were more likely to be incarcerated, and to receive longer sentences if they were incarcerated, than defendants who had been released pending case disposition.
\end{abstract}

Sentencing decisions have Jong been the subject of criminal justice research, particularly research that has attempted to determine the legal and extralegal factors that influence a judge's decision. Legal factors such as offense seriousness and prior record of the defendant have perhaps occupied the most space in research of this type (Kramer \& Steffensmeier, 1993), but extralegal factors such as the race and gender of the defendant or of the victim have also been found to be related to sentencing outcomes (Steffensmeier, Ulmer, \& Kramer, 1998; Zatz, 1984). One factor, pretrial detention, is difficult to categorize as either a legal or an extralegal variable. Nevertheless, research into the effects of legal and extralegal factors has included pretrial detention as a control variable in order to determine whether it can help explain certain sentencing decisions (Holmes, Daudistel, \&Farrell, 1987).

One aspect of sentencing decisions, the decision to incarcerate, is a common focus of sentencing research. Some studies have found that legal factors overwhelmingly affect the decision to incarcerate (Kramer \& Steffensmeier, 1993), although others have found that extralegal factors are becoming increasingly prominent in imprisonment decisions (McDonald \& Carlson, 1993; Spohn \& Cederblom, 1991; Steffensmeier, Kramer, \& Streifel, 1993). It has been argued that pretrial detention also plays a role in such decisions, in that those who were detained prior to case disposition are more likely to be incarcerated and to receive a longer sentence than those who secured their release. Pretrial detention is often related to offense seriousness and prior record; thus, it could be a significant indicator of sentencing outcomes. Pretrial detention is also related to attorney type, which has been shown to affect sentencing outcomes in some studies (Taylor, Stanley, Def lorio, \& Seekamp, 1972). For these reasons it is important to examine pretrial detention while controlling for offense seriousness, prior record, and attorney type. The present article 
examines whether defendants who had been jailed pending case disposition were treated more severely than defendants who had not been jailed, controlling for related legal and extralegal factors.

\section{PREVIOUS RESEARCH ON IMPRISONMENT DECISIONS}

Much research in criminology and criminal justice focuses on the factors that influence decisions to incarcerate defendants. In general, research has been fairly consistent in finding that the primary determinants of decisions to incarcerate are such legally relevant variables as the seriousness of the offense and the offender's prior record (Gottfredson \& Gottfredson, 1988; Huang \& Finn, 1996; Neubauer, 2002; Sutton, 1978; Tiffany, Avichai, \& Peters, 1975).

Many studies that have considered the effect of legal factors on imprisonment decisions have also incorporated extralegal factors into the research. There has been considerable research that has examined the impact of such factors as the race, gender, and class of the defendant on decisions to incarcerate. Such research indicates that both legal and extralegal factors play a role in decision making. A study by Klein, Petersilia, and Turner (1990) found that such legal factors as the number of conviction counts, prior record, and the question of whether a gun was used in the commission of the offense were predictors of imprisonment decisions. In addition, these authors found that such extralegal factors as the age of the defendant and the type of counsel affected imprisonment decisions.

Another study, completed by Spohn, Gruhl, and Welch (1981), which controlled for legal factors (conviction charge, prior record) and extralegal factors (race), found that race played a role in ajudge's decision to incarcerate. This conclusion is supported by other research that has found some race effects even when controlling for legally relevant variables (Spohn \& Cederblom, 1991). Other studies, however, dispute these findings and claim that, when legally relevant variables are controlled, race effects all but disappear (Klein et al., 1990).

Gender, another extralegal factor, has also been found to play arole in sentencing decisions. Steffensmeier et al. (1993), controlling for legally relevant variables, found that females were less likely to receive imprisonment than men. This is supported by research conducted by Ulmer and Kramer (1996). Regarding sentence length, research shows that females are sentenced to shorter terms of incarceration than men (Albonetti, 1997).

Other research has assessed the impact of the combined effects of race, gender, and age of defendants on sentencing decisions. Steffensmeier et al. ( 1998) included in their research an analysis of legal factors such as prior record and offense severity and studied the interactive effects of race, gender, and age on the decision to incarcerate and on the length of sentence. Results indicated that the legal factors such as prior record and offense severity were significant predictors of the dependent variables but also indicated that younger, black, and male defendants were sentenced more harshly than older, white, and female defendants. This suggests that future research should focus on the interactive effects of extralegal variables in order to better assess their impact on sentencing decisions.

Race and gender (and sometimes age) are the primary extralegal factors that are implicated in research that examines decision making and imprisonment decisions. The fact that race and gender play a role in imprisonment decisions even when legal factors are controlled suggests that disparity does exist in sentencing decisions. There is one variable, however, that has been used as a control variable in many research projects but has not received as much attention as the more common legal and extralegal variables-pretrial detention.

\section{RESEARCH EXAMINING PRETRIAL DETENTION}

Decisions regarding pretrial detention have received some attention in the research, but questions about the effect of pretrial detention on imprisonment decisions linger because of the inability to adequately explain why or how pretrial detention has an effect on decision making. Most studies have used pretrial detention as a control variable rather than as the primary variable of 
interest. The studies that have used pretrial detention as a control variable have indicated that pretrial detention does play a role in sentencing decisions. Factors associated with bail decisions may help explain some of the factors associated with subsequent imprisonment decisions.

It is generally known that the higher the bail amount the less likely it is that a defendant will be released prior to trial (Zeise!, 1979). According to the Bureau of Justice Statistics (1993), when bail is set at $\$ 50,000$ or more, only 1 out of 8 defendants (roughly 12 percent) secure their release. When bail is less than $\$ 5,000$, only about 60 percent of defendants secure their release. The fact that 40 percent of defendants with bail set at less than $\$ 5,000$ are not released raises the issue of economic biases in bail decisions. In effect, many defendants simply cannot afford to make bail, whereas similarly situated defendants (in terms of seriousness of offense and prior record) are able to be released prior to case disposition because they can afford to make bail. A study by Holmes et al. (1987) reveals that another economic issue, the ability to afford private counsel, directly affects bail status. The authors contend that defendants who lack private counsel are less likely to be released pending case disposition. Thus, it appears that there is a snowball effect with regard to economic resources and bail. Having a private attorney may indicate that a defendant has the resources to make bail, or it may enable a defendant to decrease the bail amount or eradicate it altogether. Those defendants without private attorneys may not benefit from this practice and this may make it more difficult for them to be released.

With regard to bail decisions, studies point out that the seriousness of the offense and the prior record of the defendant are the most important factors in determining whether bail will be set and, if so, how much it will be (Goldkamp \& Gottfredson, 1985). Neubauer (2002) states that jail overcrowding also plays a role in bail decisions. Ifdefendants must go to jail because of bail decisions, either because bail is denied or because bail is set too high, jails must accommodate another body or let someone else go. Another issue involving bail decisions is that, although states provide guidelines forjudges to follow, judges have considerable discretion when making a bail decision (Neubauer, 2002). In addition, because bail hearings occur only a short time after arrest,judges have little information on which to make bail decisions (Gottfredson \& Gottfredson, 1988). Typically, ajudge knows little about a defendant's ability to make bail, support a family, etc., and may set bail at levels that are unrealistic and impossible for many defendants to meet.

Preventive detention is also a factor in making bail decisions. Judges may deny bail to individuals who they believe are at risk of committing further crimes if released. On the other hand, a judge may free a defendant who is a substantial risk to the community. Preventive detention has come under fire by some who feel that judges are not qualified to make decisions about a person's future behavior. Predicting behavior in general is difficult, but some feel that judges in particular do not have enough available information to make such an important decision (Gottfredson \& Gottfredson, 1988). According to Gottfredson and Gottfredson, such prediction is difficult, and the authors point out that when such a decision is made affecting an individual's liberty it typically involves over prediction rather than under prediction-judges are more likely to jail a defendant who is no risk to the community at all.

In addition to the potential for economic bias and various prediction problems associated with bail decisions, the impact of these bail decisions is cause for concern. Research indicates that pretrial detention has an impact on sentencing and imprisonment decisions.

\section{THE EFFECT OF PRETRIAL DETENTION ON IMPRISONMENT DECISIONS AND WHAT IT MEANS}

Research that has assessed the effect of pretrial detention on sentencing decisions has typically found that such detention is related to certain case outcomes. Regarding sentencing decisions in general, a study by Goldkamp (1980) asserted that pretrial detention had no effect on findings of guilt. This is also reflected in a study by Eisenstein and Jacob (1977), who stated that pretrial detention had no overall impact on guilt decisions. In contrast, a recent study by 
Hart and Reaves (1999) examined data on felony defendants in the 75 largest cities in the United States and found that defendants who had been detained prior to case disposition were convicted almost 80 percent of the time, whereas defendants who had been released were convicted 66 percent of the time.

Questions about the effect of pretrial detention on guilt decisions may not be completely answered at this time, but research examining the role of pretrial detention in imprisonment decisions appears to be fairly consistent. Lizotte (1978) has stated that release on bail generally contributes to favorable dispositions. The first systematic investigation of the effects of bail, the Vera Institute's Manhattan Bail Project, found that defendants who had been detained pending case disposition were more likely to be sentenced to incarceration and had longer sentences than those who had been released (Ares, Rankin, \& Sturz, 1963). These findings are supported by Taylor et al. (1972) and by Hermann, Single, and Boston (1977). In both of these studies, pretrial detention was used as a control variable (along with other legal and extralegal variables) in an assessment of the effect of counsel on case outcomes. Both studies found that pretrial detention was a significant predictor of incarceration---detained defendants were more likely to be incarcerated than defendants who had been released. These findings are echoed in research conducted by Goldkamp (1980), who found that, although pretrial detention did not affect guilt decisions, detained defendants were more likely to be sentenced to prison . A study by Klein et al. (1990) found that a judge's decision to sentence an offender to prison was influenced by a number of factors. Legal factors such as the number of conviction counts, the prior record of the defendant, and the question of whether a weapon was used in the commission of the offense were significant predictors of a prison sentence. Other factors affecting a judge's decision to incarcerate were the defendant's age, the type of counsel, and the issue of whether the defendant had been detained prior to trial.

Given the findings of the effect of pretrial detention on sentencing, what are some possible explanations for this effect? The following hypotheses are based on the results of previous research.

\section{Pretrial Detention as a Legal Variable}

One explanation for the association of pretrial detention with sentencing decisions is that pretrial detention is related to legally relevant variables that play a large role in decisions to incarcerate. Pretrial release decisions are determined in large part by offense seriousness and prior record of the defendant, and the same considerations are key factors in sentencing decisions. In effect, pretrial detention is simply a proxy for offense seriousness and prior record; therefore, it is likely to be associated with sentencing decisions.

\section{Economic Bias}

Economic biases-and, relatedly, the type of counsel-also play a role in pretrial release and sentencing decisions. According to Reaves (2001), in an assessment of the 75 most populous counties in the country, it was found that only about 1 in 5 defendants were able to secure their release, either because bail was set at an amount that the defendant could not afford or because the defendant was denied bail. As mentioned earlier, the study by the Bureau of Justice Statistics (1993) showed that 40 percent of defendants with bail amounts less than $\$ 5,000$ were not able to secure their release. Defendants who are poor or unemployed are less likely to be able to secure their release if a bail amount is set. Thus, these individuals are subject to deprivations that are not encountered by defendants who may be more financially stable. Regarding sentencing practices, Chiricos and Bales (1991) argue that defendants who are unemployed received more severe sentences than employed defendants. Box and Hale (1985) argue 
that judges view unemployment as a threat and that unemployed individuals are regarded as somehow more dangerous and are sentenced accordingly. This finding is supported in research by Spohn and Holleran (2000), especially for defendants who are young and are members of a minority group. Thus, defendants who are poor and unemployed are faced with two strikes against them . Because of their economic situation, they are unable to secure their release on bail. In addition, if unemployed defendants are perceived as dangerous by judges, this, in turn, can negatively affect both their bail status and subsequent sentencing.

Research by Holmes et al. (1987) and Taylor et al. (1972) indicates that pretrial release decisions are influenced by the presence of private counsel. In effect, defendants who do not have access to private counsel may not be able to afford bail, to argue successfully for their release, or to negotiate favorable bail decisions. Research has shown that some defendants receive substandard representation from appointed attorneys, especially if the attorneys operate in a jurisdiction that has an excessive caseload and inadequate resources to compensate for the caseload (Ogletree, 1995; Schulhofer \& Friedman, 1993). Research by Holmes, Hosch, Daudistel, Perez, and Graves (1996) indicated that unemployed defendants were less likely to be represented by private attorneys or to be released prior to case disposition. Those defendants received more severe sentences than defendants who had private attorneys and who had been released pending case disposition. It could be argued that jailed defendants do not receive adequate representation and do not have the opportunity to effectively assist in their defense; that is, jailed defendants cannot assist with investigations or confer freely with their lawyers. Thus a defendant's economic status affects the type and quality of representation, which in turn can affect the outcome of a case.

\section{Perceptions and Prediction by Judges}

Another explanation involves perceptions of dangerousness and faulty predictions by judges. As mentioned above, Box and Hale (1985) claim that judges may perceive unemployed defendants as more dangerous than employed defendants. The authors suggest that judges have the notion that unemployment causes crime and that the need to control this "problem population" is evident in bail and sentencing practices against unemployed defendants. In addition, Steffensmeier et al. (1998) suggest that judges perceive younger, male, and black offenders as more of a threat to the community than older, female, and white offenders because they are committed to the street life, show less remorse, and are better able to "do the time." Prediction of behavior, as noted earlier, is an inexact science, and Gottfredson and Gottfredson (1988) suggest that judges' predictions regarding defendant behavior are weak, have low validity, and involve substantial over prediction. Given this, a judge may feel that a defendant is more dangerous than he or she actually is, and this plays a role in both bail and sentencing decisions. In effect, a judge may decide not to release a perceived dangerous individual into the community, whether this decision involves pretrial detention or incarceration after conviction. In fact, a study by Spohn and DeLone (2000) indicated that sentencing decisions reflect "stereotypes of dangerousness . . . that rest, either explicitly or implicitly, on considerations of ... pretrial status and willingness to plead guilty" (p. 30).

Another factor that could explain why such a small percentage of defendants are able to secure their release involves the perceived flight risk of the defendant. A judge can increase or deny bail for a defendant who the judge feels will not appear at future court dates or will be unable to abide by conditions of release, especially if it has happened in the past. A judge's perception of flight risk or of inability to abide by release conditions, or a defendant's history of skipping court dates, could have an impact on sentencing decisions. If a judge feels that a defendant needs constant supervision or would be unable to complete certain conditions of release, the judge may be more likely to incarcerate the individual rather than place him or her on probation (see, generally, Gottfredson \& Gottfredson, 1988). 


\section{Family Concerns}

Another factor associated with defendants remaining in jail pending case disposition involves family concerns. Ifa defendant has a stake in the community or has a family to support; judges may be less likely to impose pretrial detention. The same holds true for sentencing. Daly (1994) suggests that factors associated with stability and conventionality, including employment and care of others, are related to sentencing practices.

Given the issues surrounding pretrial detention and factors related to its effects on imprisonment decisions, the current article was able to assess some of the hypotheses listed above. Based on previous research, it appears that judges consider the same factors in sentencing decisions that they consider in bail decisions. If this is the case, then the effect of pretrial detention in the current article should be eclipsed by other variables that are perhaps stronger predictors of sentencing decisions (seriousness of the offense, prior record, etc.). To determine whether pretrial detention is a predictor of imprisonment decisions, even when other predictors are controlled, the current article included the legal variables of offense seriousness and prior record to examine the hypothesis that the effect of pretrial detention is simply a reflection of legal factors. Additionally, a test of economic bias is presented in the current article by including an attorney variable to account for perceived inequities with regard to representation. Unfortunately, the current article was unable to acquire information on each defendant's employment status. Interactive controls for gender and race of the defendant (based on the research by Steffensmeier et al., 1998) were included to account for sentencing practices that could be explained by these effects. If pretrial detention is a predictor of imprisonment decisions despite the presence of control variables, some of the hypotheses mentioned above will have to be reconsidered.

\section{METHODOLOGY}

Data for the current article were gathered from Leon County, Florida, which has a population of slightly more than 200,000 and is home to the state capital. Data were gathered on adult felony cases that closed during the period from January 1, 1994, to December 31, 1996. Information on the cases was obtained from files in the office of the Clerk of Court, Felony Division.

Approximately 10,000 felony cases were closed during the study time period. A sample of 412 cases was used to examine the research question. Because of the relative infrequency of private counsel (the public defender system of Leon County handles approximately 80 percent of all criminal cases), this value was oversampled to ensure an adequate comparison of private counsel and appointed counsel in the analyses. Thus, the sampling frame was divided into two categories-cases involving private counsel and cases involving appointed counsel. The cases in each attorney group were organized chronologically by case number, and a systematic random sample was employed for each group. A total of 180 cases were selected from the list of cases with private counsel, and 240 cases were selected from the list of cases with appointed counsel. Because the current article examined the effect of pretrial detention on imprisonment decisions (not decisions of guilt), cases that involved dismissals (6 cases) and acquittals (2 cases) were not included, as these cases did not involve any sort of sentencing decision. The remaining 412 cases resulted in guilty pleas. To better test the effects, guilty pleas provide a 100 percent guarantee of a sentence; thus, it is reasonable to include only these types of dispositions. The sample also included cases that were closed in previous years but were reopened and subsequently closed again during this time period because of some activity on the part ofthe defendant or the court. Those who were released from prison or whose probation was terminated were not included in the sample. 
Although this is a small sample, the number of cases used in the analyses is more than that recommended by Tabachnick and Fidell (1989) and by Nunnally (1978) to achieve results without substantial. bias or error. In addition, the use of a systematic random sample of cases ensured that observer bias was kept at a minimum and made the achievement of a representative sample more likely. Table 1 provides a list of the variables in the analysis.

\section{Dependent Variables}

Two sentence variables were analyzed. This article assessed the relationship between pretrial detention and the issues of whether a defendant was incarcerated and, if so, the length of incarceration. At the time of this study, the state of Florida allowed split sentences. In this article, however, none of the cases sampled consisted of split sentences. As a result, analyses were conducted using cases that received either probation or incarceration.

\section{Incarceration}

This variable assessed whether convicted defendants were sentenced to jail or prison $(0=$ No, 1 $=$ Yes).

\section{Length of Sentence}

For those convicted defendants who were sentenced to a term in jail or prison, the length of that sentence was measured in days.

\section{Independent Variables}

\section{Pretrial Detention}

The primary variable of interest in this article was pretrial detention. This variable distinguished between those defendants who had been released prior to case disposition (coded 0) and those defendants who had been jailed (coded 1).

\section{Seriousness of Charge}

The seriousness of the charges against a defendant could have a significant impact on bail and imprisonment decisions. To assess the seriousness of the charge or charges against a defendant in this article, two measures were used. The first measure, Felony Charges, assessed the number of felonies with which a defendant was charged. For descriptive purposes, Table 1 provides a breakdown of the number of felony charges for the defendants in the sample; in the actual analysis, the ratio measure was used. To assess the degree of the charge, another measure, Type of Charge, assessed whether the defendant was charged with a major felony (1st degree or 2 nd degree) versus other felonies. This variable was coded as "minor felony" (coded 0 ) or "major felony" (coded 1). Under Florida law, the number of felonies charged and the degree of felony combine to determine the seriousness of the charge. It was hypothesized that being charged with numerous felonies or with a major felony would carry more weight in determining a sentencing decision than being charged with single or minor felonies. It should be noted that in Florida's sentencing system misdemeanor convictions have a minimal effect on a defendant's sentencing score; therefore, they were not included in the analyses. 
Table 1

Variables in the Analyses $(N=412)$

\section{Dependent variables}

Incarceration

$$
\begin{aligned}
& \text { No }=185(45 \%) \\
& \text { Yes }=227(55 \%)
\end{aligned}
$$

Length of sentence, in days, if incarcerated

Mean $=397$ days

\section{Independent variables}

Bail status

Released $=284(69 \%)$

In jail $=128(31 \%)$

Offense type

Minor felony $=300(73 \%)$

Major felony $=112(27 \%)$

Number of felony charges

Mean $=1.81$

$1=308(75 \%)$

$2-4=83(20 \%)$

$>4=21(5 \%)$

Number of prior felony convictions

Mean $=1.13$

$0=234(57 \%)$

$1-3=133(32 \%)$

$>3=45(11 \%)$

Attorney type

Appointed $=177(43 \%)$

Retained $=235(57 \%)$

Length of disposition

Mean $=131$ days

Race/gender of defendant

Black male $=194(47 \%)$

White male $=135(33 \%)$

White female $=32(8 \%)$

Black female $=51(12 \%)$

Age of defendant

Mean $=29.6$ years 


\section{Prior Record}

Prior record could have a significant impact on decisions. To assess prior record, a ratio measure and the actual number of previous felony convictions for each defendant were used. For descriptive purposes, Table I provides a breakdown of the number of previous felony convictions for defendants in the sample; in the actual analysis, the ratio measure was used.

\section{Type of Attorney}

Because of its presumed effect on bail decisions, type of attorney was controlled. Cases in this article were coded to indicate defendants with appointed attorneys (coded 0) and defendants with private attorneys (coded 1).

\section{Length of Disposition}

This variable refers to the length of time that was taken to dispose of a case. This variable has been used in previous studies because of the possibility that it could affect case outcome. Hermann et al. (1977) and the National Center for State Courts (1992) have posited that a delay is beneficial to defendants because prosecutors may be more likely to dispose of cases that have taken up time. On the other hand, it is also possible that defendants may not benefit from long delays because the prosecution is given a chance to strengthen its case or because defendant witnesses may not be easily reachable at a later date. Although the research named above dealt with case outcomes other than sentencing, there are few studies, if any, in sentencing research that have included this variable. The current article included the variable in order to examine whether the effect of longer disposition times can be extended to sentencing practices. In effect, it could be argued that, if a defendant is subject to pretrial detention for a lengthy period of time, a judge may look upon that defendant favorably at sentencing, because the defendant has already "done the time" in pretrial detention; thus, the defendant would not be punished as harshly. This variable was coded as the number of days between arrest and sentencing decision.

\section{Race/Gender}

Race and gender may influence case outcome because of their correlation with such legal factors as prior record or such extralegal factors as bias and attorney type. Based on previous research (e.g., Steffensmeier et al., 1998) that has stated that black males are the most harshly treated race-gender dyad, dummy variables were created for white male, white female, and black female, with black male as the reference category, to assess the impact of being black and male on imprisonment decisions. The dummy variables asked whether a defendant was a member of the race-gender dyad, with 0 indicating No and 1 indicating Yes.

Age

This variable was used because of its potential effect on case outcome; that is, there might be a reluctance to send very young or very old defendants to prison. For this variable, the actual age of the defendant was coded.

One point that should be noted is that there could possibly be concerns about intercorrelation among the control variables. Bivariate correlations revealed the highest significant correlations between race of defendant and attorney type (Pearson's $r=-.33$ ), 
between bail status and number of prior felony convictions (Pearson's $r=.30$ ), and between bail status and attorney type (Pearson's $r=.20$ ). For these reasons, interaction terms for these variables were included in each analysis to account for correlation effects. In each analysis, the interaction terms were not significant.

\section{RESULTS}

Table 1 provides a descriptive summary of the relevant variables. Regarding legal variables, a majority of defendants were charged with minor felonies. The mean number of felony charges was 1.81 and the mean number of prior felony convictions was 1.13. Thus, most defendants in this article were relatively minor felony offenders with less serious prior records. Regarding extralegal variables, almost half of the defendants (47 percent) were black males and the mean age of the defendants was 29.6 years. A majority of defendants also had retained attorneys, but this majority was due to oversampling of retained attorneys, as discussed earlier. Regarding the primary variable of interest, pretrial detention, a majority of defendants were out of jail pending case disposition.

Table 2 provides the results of a logistic regression analysis examining whether defendants were incarcerated after pleading guilty. In this analysis, both legal and extralegal factors were significant at the .0I alpha level. Regarding legal variables, a defendant charged with a major felony was more likely to be incarcerated (2.530 odds ratio). Also, those with more prior felony convictions were more likely to be incarcerated (I .295 odds ratio). This was expected, considering the fact that offense seriousness and prior record are major predictors of incarceration. Regarding extralegal variables, use of dummy variables for the race-gender interaction indicated that white males, white females, and black females were all less likely to be incarcerated than black males.

The primary variable of interest, pretrial detention, was also significantly associated with incarceration. Defendants who had been detained prior to case disposition were more likely to be incarcerated (6.023 odds ratio). In fact, in comparisons of pretrial detention with the other variables, pretrial detention was the strongest predictor of incarceration, even when controlling for legally relevant and extralegal variables.

Table 3 illustrates the results of an OLS regression analysis that assessed the length of incarceration for those who were sentenced to imprisonment. Regarding legal variables, the number of felony charges was significant, in that defendants charged with multiple felonies were sentenced to longer terms of incarceration than defendants charged with fewer felonies. Also, defendants charged with major felonies were sentenced to longer terms of incarceration than defendants charged with minor felonies, although the relationship was significant at a lower alpha level. 
Table 2

Logistic Regression Analysis for Incarceration $(N=412)$

\begin{tabular}{lccc}
\hline Variable & B & S.E.* & Odds ratio \\
\hline Detained prior to trial & 1.796 & .309 & $6.023^{* *}$ \\
Major felony charge & .928 & .286 & $2.530^{* *}$ \\
Number of felony charges & -.123 & .082 & .884 \\
Number of prior felony convictions & .259 & .082 & $1.295^{* *}$ \\
Private attorney & -.101 & .262 & .904 \\
Length of disposition & .001 & .001 & 1.001 \\
Age of defendant & -.003 & .012 & .997 \\
White male defendant & -.357 & .281 & $.700^{* *}$ \\
White female defendant & -.537 & .472 & $.585^{* *}$ \\
Black female defendant & -1.436 & .410 & $.238^{* *}$ \\
Constant & -2.927 & .788 & \\
\hline
\end{tabular}

Note. $-2 \log$ likelihood $=438.347$.

-S.E. $=$ standard error.

$* 0<.01$.

Table 3

OLS Regression Results for Length of Sentence $(\boldsymbol{n}=227)$

\begin{tabular}{lrc}
\hline Variable & B & S.E.' \\
\hline Detained prior to trial & 357.407 & $108.460^{* *}$ \\
Major felony charge & 275.395 & $104.848^{*}$ \\
Number of felony charges & 205.491 & $46.677^{* *}$ \\
Number of prior felony convictions & 22.140 & 26.030 \\
Private attorney & -45.323 & 115.469 \\
Length of disposition & .863 & $.279^{* *}$ \\
Age of defendant & -8.091 & 6.251 \\
White male defendant & -162.282 & $122.031^{* *}$ \\
White female defendant & -487.374 & $225.216^{* *}$ \\
Black female defendant & -75.751 & $210.407^{* *}$ \\
Constant & -613.021 & 343.984 \\
\hline
\end{tabular}

Note. $R^{2}=.33$.

-S.E. $=$ standard error.

${ }^{*} p<.01 . * *<.05$. 
Another significant variable, which is not considered legal or extralegal, was length of disposition. Defendants with longer case dispositions were sentenced to slightly longer sentences than defendants with shorter case dispositions. In addition, results indicated that, again, black male defendants were treated more harshly than other defendants. White males, white females, and black females were all sentenced to shorter imprisonment terms than black males. The primary variable of interest, pretrial detention, was again significant at the .01 level. Defendants who had been in jail pending case disposition received longer imprisonment terms than defendants who had been released pending disposition. This corresponds with the results of the logistic regression analysis-pretrial detention remained significant even when legal variables were controlled.

\section{DISCUSSION}

Previous research has noted the significance of the effect of pretrial detention on sentence outcomes. Whether pretrial detention is seen as a legal factor (related to offense seriousness and prior record) or as an extralegal factor (related to the economic status of the defendant), its role cannot be ignored. The current article examined the relationship between pretrial detention and imprisonment decisions after guilty pleas had been entered in order to determine whether the effects of pretrial detention remained in the presence of legal and extralegal variables.

Results of this article indicate that pretrial detention was a strong, significant predictor of both incarceration and length of sentence. Legal factors were also significant in both analyses-offense seriousness and prior record for incarceration, offense seriousness for length of sentence. This supports previous research (Klein et al., 1990; Steffensmeier et al., 1998). Black males were treated more harshly in terms of both incarceration and sentence length. This also supports the previous research conducted by Steffensmeier et al. (1998). An interesting note is that length of disposition was significant for length of sentence. The slightly longer sentences for cases with longer disposition times could be a reflection of the ability of prosecutors to get more evidence against a defendant. Itcould also indicate that the charges against the defendant were rather serious and that the prosecution was being diligent in its actions.

What does this mean for the primary variable of interest? Although a majority of defendants had been out ofjail pending disposition, their pretrial detention status was associated with different sentencing outcomes. It could be argued that, because it is related to offense seriousness and prior record, pretrial detention is essentially another legal variable in the equation; thus, it would be significant. What is important to note, however, is that pretrial detention remained significant even when offense seriousness and prior record were controlled. In addition, previous research (Holmes et al., 1987; Taylor et al., 1972) has asserted that pretrial detention is related to the type of attorney that a defendant has, suggesting that economics plays a role in decisions about both pretrial detention and sentencing. For this reason, type of attorney was controlled in the current study, and pretrial detention remained significant. The remaining significance of pretrial detention after controlling for legal and extralegal factors could be explained by factors that are not reflected in the data. As mentioned earlier, defendants who are subject to pretrial detention may be the victims of prediction error, in that judges may feel that some defendants are more serious than they actually are or that they would not be amenable to probation conditions; thus, incarceration may be favored. Also, defendants who are in jail may not be able to effectively assist in their defense and this could impact the quality of representation. Judges may also consider family concerns when sentencing someone to incarceration; perhaps those who are not incarcerated have a larger stake in the community or have a family to support. One caveat is that these factors were not included in the analyses, because this information was not contained in the case files. It could be argued that pretrial detention would still be significant even with the inclusion of these variables, given the significance of pretrial detention when the other factors are controlled. 
Although it is acknowledged that judges consider the same factors in bail decisions that they consider in sentencing decisions, other factors could explain the results of this article. Judges may view defendants who were out on bail as somehow less dangerous than defendants who were subject to pretrial detention. In effect, a defendant who is out on bail has the ability to demonstrate to the sentencing judge that he or she is not a danger to the community-something that a defendant who is subject to pretrial detention cannot do. As a result, a judge may look favorably on that defendant by rationalizing that a defendant who has behaved well while out on bail may be a good candidate for community supervision, a decidedly less harsh punishment than incarceration. Therefore, it may be that judges are not treating defendants who were subject to pretrial detention more harshly but are being lenient toward defendants who were out on bail.

Another explanation that is related to the previous discussion has to do with a defendant's ability to "get his life turned around" while out on bail. Unlike a defendant who is subject to pretrial detention, a defendant who is out on bail may be able to keep (or get) a job. Also, a judge may look favorably on a defendant who is out on bail and appears for all court dates. A defendant who is out on bail can show the sentencing judge not only that he or she is not dangerous but that he or she is willing to change and has taken steps to do so. This is something that a defendant who is subject to pretrial detention cannot easily do.

\section{CONCLUSION}

For many research projects, it is difficult to explain the effects of pretrial detention on sentencing decisions. Often, the factors that judges consider in bail decisions are the same factors that they consider in sentencing decisions. As mentioned above, perhaps judges consider something else when it comes to making sentencing decisions. The ability to prove that one is not a danger to the community could be a strong force in sentencing decisions. If this is true, perhaps defendants who are subject to pretrial detention should be given the opportunity to show that they are not a danger to the community. The present findings suggest that jurisdictions consider policies that are designed to make pretrial release available to more defendants. Although this may not be applicable to defendants who are charged with violent crimes or who pose serious flight or public safety risks, defendants who are in jail for economic reasons should be given the opportunity to show that they are capable of functioning in the community. To minimize risks to public safety, monitoring of such individuals via daily reporting, electronic monitoring, etc., could be expanded to ensure success while out on bail. This would also increase the possibility that a number of defendants could assist in their own defense. Ifthis is not feasible, perhaps judges should be informed of the reasons that an individual was subject to pretrial detention prior to imposing sentence. Such information could easily be presented in a presentence investigation report. Thus judges would be made aware of defendants who are in jail simply because they cannot afford to get out, as opposed to defendants who are who in jail because they are a perceived flight risk or a danger to the community.

This article was not an attempt at a comprehensive examination of the issue at hand.It should be viewed as exploratory, and future research should examine the relationship between bail status and imprisonment decisions in a more comprehensive manner. In particular, future research should include more variables dealing with a defendant's economic status (such as unemployment) and family situation (such as being married, having children, etc.). In addition, future research should get at the heart of the matter by questioning judges on their perceptions of pretrial detention and any potential effects that it has on their sentencing decisions.

\section{REFERENCES}

Albonetti, C. (1997). Sentencing under the federal sentencing guidelines: Effects of defendant characteristics, guilty pleas, and departures on sentencing outcomes for drug offenses, 1991-1992. Law and Society Review, 31, 789-822. 
Ares, C., Rankin, A., \& Sturz, H. (1963). The Manhattan Bail Project: An interim report on the use of pretrial parole. New York University law Review, 38, 67-92.

Box, S. , \& Hale, C. (1985). Unemployment, imprisonment, and prison overcrowding. Contemporary Crises, 9, 209-228

Bureau of Justice Statistics. (1993). Jail inmates 1992. Washington, DC: United States Department of Justice. Chiricos, T., \& Bales, W. (1991). Unemployment and punishment: An empirical assessment. Criminology, 29, 701-724.

Daly, K. (1994). Gender, crime, and punishment. New Haven, CT: Yale University Press. Eisenstein , J., \& Jacob, H. (1977). Felonyjustice : An organizational analysis of criminal courts. Boston: Little, Brown.

Goldkamp, J. (1980). The effects of detention on judicial decisions: A closer look. Justice System Journal, 5, 234-257.

Goldkamp, J., \& Gottfredson, M. (1985). Guidelines for bail: The Philadelphia experiment. Philadelphia: Temple University Press.

Gottfredson, M., \& Gottfredson, D. (1988). Decision-making in criminaljustice : Toward the rational exercise of discretion. New York: Plenum Press.

Hart, T., \& Reaves, B. (1999). Felony defendants in large urban counties, 1996. Washington, DC: Bureau of Justice Statistics.

Hermann, R., Single, E., \& Boston, J. (1977). Counselfor thepoor . Lexington, MA: Lexington Books.

Holmes, M., Daudistel, H.,\& Farrell, R. (1987). Determinants of charge reductions and final dispositions in cases of burglary and robbery. Journal of Research in Crime and Delinquency, 24, 233-254.

Holmes, M., Hosch, H., Daudistel, H., Perez, D., \& Graves, J. (1996). Ethnicity, legal resources, and felony dispositions in two southwestern jurisdictions. Justice Quarterly, 13, 11-30.

Huang, W., \& Finn, M. (1996). Individual and contextual influences on sentence lengths:

Examining political conservatism. Prison Journal, 76, 398-420.

Klein, S., Petersilia, J., \& Turner, S. (1990). Race and imprisonment decisions in California. Science, 247, 812-816.

Kramer, J ., \& Steffensmeier, D. (1993). Race and imprisonment decisions. Sociological Quarterly, 34,357-376.

Lizotte, A. (1978). Extra-legal factors in Chicago's criminal courts: Testing the conflict model of criminal justice.

Social Problems, 25, 564-580. 
McDonald, D., \& Carlson, K. (1993). Sentencing in thefederal courts: Does race maller ? The transition to sentencing guidelines, 1986-1990. Washington, DC: Bureau of Justice Statistics.

National Center for State Courts. (1992). Indigent defenders: Get thejob done and done well. Washington, DC: National Center for State Courts.

Neubauer, D. (2002). America's courts and the criminaljustice system. Belmont, CA: Wadsworth. Nunnally, J. (1978). Psychometric theory. New York: McGraw-Hill.

Ogletree, C. (1995). An essay on the new public defender for the 21st century. lawand Contemporary Problems,

58, 81-93.

Reaves, B. (2001). Felony defendants in large urban counties, 1998. Washington, DC: Bureau of Justice Statistics.

Schulhofer, S.,\& Friedman, D. (1993). Rethinking indigent defense:Promoting effective representation through consumer sovereignty and freedom of choice for all criminal defendants. American Criminal Law Review, 31, 73-122.

Spohn, C., \& Cederblom, J . (1991). Race and disparities in sentencing: A test of the liberation hypothesis . Justice Quarterly, 8, 305-328.

Spohn, C., \& Delone, M. (2000). When does race matter? An analysis of conditions under which race affects sentence severity. In J. Ulmer (Ed.), Sociology of crime, law, and deviance, Volume 2 (pp. 337). New York: Elsevier.

Spohn, C., Gruhl, J ., \& Welch, S. (1981). The effect of race on sentencing: A re-examination of an unsettled question. Law and Society Review, 16, 71-88.

Spohn, C., \& Holleran, D. (2000). The imprisonment penalty paid by young, unemployed black and Hispanic offenders. Criminology, 38, 281-306.

Steffensmeier, D., Kramer, J., \& Streifel, C. (1993). Gender and imprisonment decisions. Criminology, 31, 411-443.

Steffensmeier, D., Ulmer, J.,\& Kramer, J. ( 1998). The interaction of race, gender, and age in criminal sentencing: The cost of being young, black, and male. Criminology, 36, 763-798.

Sutton, L. (1978). Variations in federal criminal sentences: A statistical assessment at the national level. Washington, DC: National Criminal Justice Information and Statistics Service.

Tabachnick, B., \& Fidell, L. (1989). Using multivariate statistics. Cambridge, MA: Harper and Row.

Taylor, J., Stanley, T., Def lorio, B., \& Seekamp, L. (1972). An analysis of defense counsel in the processing of felony defendants in San Diego, California. Denver law Journal, 49, 233-275.

Tiffany, L., Avichai, Y., \& Peters, G. (1975). A statistical analysis of sentencing in federal courts: Defendants convicted after trial, 1967-68. Journal of legal Studies, 4, 397-417.

Ulmer, J., \& Kramer, J. ( 1996). Court communities under sentencing guidelines: Dilemmas of formal 
rationality and sentencing disparity . Criminology, 34, 383-407.

Zatz, M. (1984). Race, ethnicity, and determinate sentencing: A new dimension to an old controversy.

Criminology, 22, 147-171.

Zeise!, H. (1979). Bail revisited . American Bar Foundation Research Journal, 1979, 769-789. 